\title{
Reviewable Unit
}

National Cancer Institute

\section{Source}

National Cancer Institute. Reviewable Unit. NCI Thesaurus. Code C70721.

A predefined portion of an application that, by agreement between the applicant and the review division, can be submitted prior to submission of a complete application. 